\title{
The meaning of health and illness: some considerations for health psychology
}

\author{
Evely Boruchovitch ${ }^{1}$ \\ Birgitte R. Mednick ${ }^{3}$
}

\begin{abstract}
The importance of understanding individuals' ideas of health and illness is well acknowledged by research for its theoretical and practical implications for both health psychology and education. Insofar as researchers agree that individuals' ideas of health and illness have an impact on their health attitudes and behaviour, people's thoughts of health and health and illness - related issues are increasingly being investigated. In consonance, the objective of this study is to critically review major ideas that underlies individuals' concepts of health and illness. Findings are discussed in terms of their potential contributions for health psychology.

Keywords: Concept of health; Concept of illness; Health psychology.
\end{abstract}

\section{O significado de saúde e doença: algumas considerações para a psicologia da saúde}

\begin{abstract}
Resumo
A importância de se conhecerem os conceitos de saúde e da doença dos indivíduos vem sendo reconhecida pelos pesquisadores da área pelas suas implicações teóricas e práticas para a psicologia da saúde e da educação. Como as evidências vêm sugerindo que as cognições relativas à saúde e doença exercem um impacto nas atitudes ligadas à saúde e no engajamento em comportamentos saudáveis das pessoas, esses conceitos estão sendo cada vez mais investigados. Em consonância, o objetivo deste trabalho é rever criticamente a literatura a respeito dos fatores subjacentes às concepções de saúde e doença dos indivíduos. Os dados são discutidos quanto a suas potenciais implicações para a psicologia da saúde.
\end{abstract}

Palavras-chave: Conceito de saúde; Conceito de doença; Psicologia da saúde.

\section{Introduction}

Historically, the word health appeared approximately in the year 1000 A. D. Dolfman (1973) and Balog (1978) studied the roots of the concept of health. The word originally came from Old English and it meant the state and the condition of being sound or whole. More precisely, health was associated not only with the physiological functioning, but with mental and moral soundness, and spiritual salvation, as well. Though the word health has often been preceded by both positive and negative qualifiers such as good, bad or poor, it has always been regarded as a positive entity.

For the ancient Greeks, health was always an attribute of paramount importance. Their initial ideas of health as a divine responsibility and illness as a supernatural phenomenon were replaced by their recognition of the relevance of personal life habits and environmental factors for men's health status. The Greeks' ideas of health and illness have undoubtedly exerted a major impact on the Western views of health. However, with advances in the fields of medicine, science, sociology, psychology, and politics, the more philosophical theories of health began to be challenged and substituted by more scientific ones.

Insofar as researchers agree that individuals' ideas of health and illness have an impact on their health attitudes and behaviour, people's thoughts of health and health - related issues are increasingly being investigated. In consonance, the objective of this study is to critically review major ideas that underlie individual's concepts of health and illness. Findings are discussed in terms of their potential contributions for health psychology.

\section{The Meaning of Health}

As suggested by Balog (1978), three major views of health have emerged in more recent time: (a) the traditional medical concept, (b) the World Health Organization concept, and (c) the ecological concept. A

\footnotetext{
${ }^{1}$ Professor Assistente Doutor - Faculdade de Educação - Departamento de Psicologia Educacional

2 Endereço para correspondência:

Rua Coronel Quirino 910 apt. 24 - Cambuí - Campinas-SP - 13025-001

E-mail: evely@,obelix.unicamp.br

${ }^{3}$ Professor Associado School of Education - Department of Educational Psychology
} 
description of these views, as well as their major assumptions and problems will be presented next.

\section{The Traditional Health Concept}

The earliest notion of health as a disease-free state represents the traditional medical concept. This view of health was largely accepted during the first half of the twentieth century, mainly between physicians and medical personnel. As described by Balog (1978), such a traditional medical concept of health was based on the assumption that health and disease were objective and observable phenomena. Developments in the areas of anatomy, bacteriology and physiology contributed to this view.

Rather than representing the presence of certain attributes, health was therefore defined solely in terms of the lack of disease, symptoms, signs or problems. Major pitfalls of this view of health were both that it conceptualized health emphasising illness, and that it neglected the individual as a whole by overemphasising specific diseases and parts of the body. Additionally, this traditional view of health assumed there is a dichotomy between health and illness which according to Hinkle (1961) may not be necessarily the case. To be healthy, individuals do not necessary need to be in an absolute disease-free state, but they probably will have less disease than unhealthy people. Thus, the absence of disease, symptoms or problems may not be strong enough delimiters of a healthy state.

\section{The World Health Organization Concept of Health}

In the late 1940's, the World Health Organization developed a more holistic concept of health as "a state of complete physical, mental and social well-being and not merely as the absence of disease or infirmity" (p. 1-2, 1947). Rather than restricting health to an absence of illness, health was conceptualized more in terms of the presence of absolute and positive qualities.

This holistic and more utopian view of health encompasses and extends the traditional medical view by conceiving health as a positive state of well-being in which physical health is only one of the aspects involved. Along with that, social, psychological, physical, economic and political aspects were incorporated in the definition of health, and regarded as components of paramount importance for health and well-being. By adding the psychological and social criteria, the authors of the World Health Organization concept of health not only acknowledged that health and illness are essentially multicausal, but also shifted the focus from a strictly medical perspective in which absence of illness was the criteria used to evaluate a person's status. The new view of health, however also presents some drawbacks since the qualities of well-being and wellness have not been clearly defined yet. By being so broad and vague, the World Health Organization concept, according to Lewis (1953), lacks specificity enough to be defined operationally and to be applied to practical situations. Moreover, the WHO definition implies an idea of a complete perfect state which is unrealistic and unreachable (Segre \& Ferraz, 1997).

\section{The Ecological Concept of Health}

More ecological and relative notions of health emerged in the 1960s and 1970s. Such perspectives differed from the previous medical and holistic approaches mainly in two aspects: first, by conceiving health as a more relative sort of concept and, second, by placing a greater emphasis on the interrelationships between the environment and the individual's quality of life. These ecological and relative definitions of health tended to be were heavily based on an evaluation of the person's level of functioning and adaptation to the environment.

Within the more function-oriented perspectives, health has been defined either in terms of an adequate functional capacity which allows the individuals to carry out their duties and responsibilities (Oberteuffer, 1960), or in terms of a certain quality of life which enables individuals to live happily, successfully, fruitfully, and creatively (Williams,1946; Bauer \& Schaller, 1955; Hoyman, 1962). Parsons (1958) differentiated between physical and mental health functioning. Mental health level was defined in terms of individual's ability to carry out institutionalised social roles, while the evaluation of somatic health was based on the individual's effectiveness in accomplishing valued tasks.

Alternatively, in ecological approaches more geared towards associating health with adaptation, health has been conceptualized as individuals' capacity to adjust adequately to their environment. "The state of health and disease are expressions of the success and failure experienced by the organism in its effort to respond adaptively to environmental changes" (Dubos 1965, p. xvii). In a similar vein, Dunn (1959) extended the conception of health by introducing the notion of wellness as the integration of both people's capacity to function in their environment, and their ability to adjust to environmental stresses.

The ecological views of health also present some difficulties. Individuals may adequately adapt but, as mentioned by Lewis (1953), there are no clear distinctions between what constitutes a healthy and an unhealthy adaptation. Individuals may in fact adapt to a sick, morbid or disease-provoking condition. By the same token, individuals may indeed be sick, though able

Psico-USF, v. 7, n. 2, p. 175-183, Jul./Dez. 2002 
to carry out social responsibilities. Moreover, normality, proper functioning, and adaptation are socially and culturally constructed concepts. Consequently, as valuejudgement constructs, it becomes easy to conclude that what is considered healthy in one social context might not be in another (Parsons, 1958).

\section{The Search for a Universally Valid Concept of Health}

Balog $(1978,1981)$ insisted that it is not only possible, but also extremely important to attempt to integrate these different views of health into a single and unifying concept. He argued that, although evaluations of health status by nature must be somewhat subjective and relative, it is possible to establish some agreement regarding the essential criteria of this concept. Balog $(1978 ; 1981)$ defended the idea that the concept of health needs to be defined in terms of two key and inseparable criteria: (a) biological and personal functional objectives and (b) a well functioning of the individual's body and mind. While the biological functional objectives would be more general and common to all living organisms (e. g., specie preservation), the personal functional objectives would be unique to human beings (e. g., maintaining self-consciousness). Accordingly, Balog (1978) has concluded that health is "a state of body and mind-well functioning which affords man the ability to strive toward his both functional objectives and culturally desired goals" ( $p$. 115). It seems that Balog's (1978) view of health has some problems, too. His definition is not only broad, vague and subjective, but also multidimensional. Besides, he ended up with a definition of health which encompassed essentially the basic ideas from both of the ecological and WHO concepts.

Other researchers had stated that an adequate and universally valid concept of health is unattainable mostly because health is a value-laden term whose meaning is highly tied to different objectives which govern its use. In line with that, such researchers certainly agree that rather than representing a single entity (e.g. absence of illness), health refers to a number of entities and therefore, is a multidimensional concept (Parsons, 1958; Baumann, 1961; Dolfman, 1974; Natapoff, 1978; Balog, 1978, 1981; Kalnins \& Love, 1982; Eberst, 1984; Laffrey, 1986).

In contrast to Balog's $(1978,1981)$ ideas, Smith (1981) proposed that the multiple views of health be organized into four distinct models: (a) clinical, (b) roleperformance, (c) adaptive and, (d) eudaimonistic. It is noteworthy that these models are reminiscents of the previously existing medical, ecological and World Health Organization's definitions of health. However, Smith (1981), rather than describing the four models as mutually exclusive, advocated was the existence of an inclusive progression among them. In other words, the clinical model would represent the minimal conception of health (absence of illness) whereas the eudaimonistic model would express the most encompassing view of health. As a consequence, this latter and broadest view of health not only would include the basic premises of the three precedents, but also would go beyond them by bringing about issues of self-actualization and selffulfilment as very relevant components of health.

As can be seen, there have been several efforts to define health, and to construct a unique and universally valid concept of health. However, evidence suggests that currently, all these views of health raise some concerns. Although theorists show considerable disagreement as to which and how many components the concept of health actually has, there are some areas of consensus. For instance, most of the researchers would certainly agree that health is a multidimensional construct, and that a universally valid concept of health is unattainable (Parsons, 1958; Baumann, 1961; Dolfman, 1974; Natapoff, 1978; Kalnins \& Love, 1982; Eberst, 1984; Laffrey, 1986). The lack of a universally accepted concept of health, however, has in no way impeded the research in this area. As long as researchers consider that individuals' ideas of health and illness exert an influence on their health attitudes and behaviours, people's concepts of health and health and illness-related issues are increasingly being explored.

\section{The Meaning of Health: Empirical Findings with Children and Adolescents}

The meaning of health has been investigated among children, adolescents and adults. A mojor focus of the literature in this area has been on identifying variables that are most powerful in affecting individuals' understanding of health.

Data from studies with children and adolescents generally suggest that health is described essentially in terms of four major notions: "Health Practices", "Not Being Sick", "Feeling Good" and "Being Able to Do the Desired and/or Required Activities". The majority of studies were geared toward exploring relationships between individuals' health concept and a very limited number of (mostly sociodemographic) predictor variables. Among the predictor variables included, age and cognitive development were the most predictive of differences in subjects' health concepts (Rashkis, 1965; Natapoff, 1978; Altan, 1982; Millstein \& Irwin, 1987; Schall, Jurberg, Boruchovitch, Felix-Sousa, Rozemberg \& Vasconcellos, 1987; Natapoff \& Essoka, 1989.) 
Although there is considerable agreement regarding the influence of age and cognitive development on the development of the concept of health, research is less conclusive in terms of what indeed is the expected progression of the definitions of a health concept as a function of age. There is some evidence to suggest that older subjects are more diverse in themes defining health than their younger counterparts. Additionally, most of the studies found that the notions of health as a "Positive Feeling" and as "Not Being Sick" increased with age. Health as "Health Practices" followed an opposite trend. According to Natapoff and Essoka's (1989), there is some reason to believe that in addition to age and cognitive development, socio-historical influences may also modify and shape individuals' views of health. It appears however, that such contextual influences do not necessarily represent a move away from developmental trends, but an acknowledgement of an alternative and non-mutually-exclusive factors to which variations in individuals' health concept can be associated.

\section{The Meaning of Health: Studies of Adults}

There have been three majors approaches to the study of health concepts among adults: (a) descriptive studies aimed at understanding individuals' ideas of health (Baumann, 1961; Schall e colaboradores, 1987), (b) investigations target at developing measures of health conceptions (Laffrey, 1986; Wallston, Wallston \& Devillis, 1978), and (c) research attempting to explore potential links between a certain conception of health and actual healthy behaviour (Laffrey, 1983, 1986; Segall \& Wynd, 1990).

Baumann (1961) explored the ideas of health among medical students and patients. The group of patients were from low SES, their age ranged from 14 to 90 years old $(X=56)$ and educational background varied from no schooling to college degreed. In contrast, the medical students were from upper SES, around their twenties and had completed a college education. Health was defined in terms of three major orientations: "Feeling-State Orientation" (general feeling of well-being), "Symptom Orientation" (absence of illness), and "Performance-Orientation" (what a person who is healthy is able to do). Rather than representing a single idea, health was seen as an essentially multidimensional concept by more than half of the sample. Health concepts were found to be related to age, SES, educational background, religious orientation and current physical condition. A "Feeling-State" Orientation was more frequently found in patients than in medical students. The proportion of answers with a Feeling-State Orientation tends to decrease as the level of education increases. Medical students and younger patients were equally frequent in defining health in terms of a "Symptom-Orientation". In the patient group, the "Symptom-Orientation decreased as age increased. Jews and Protestants regarded health more in terms of a "Performance-Orientation than did Catholics. It was also interesting to note that overall, both patient and medical students defined health in terms of a "Performance-Orientation". This tendency, according to Baumann (1961), may reflect the great emphasis placed by American society on work and achievement.

Findings from a Brazilian study conducted by Schall et al. (1987) in a sample of elementary and science teachers suggested that there are both crosscultural similarities and differences in health definitions. As in Baumann's study (1961), Brazilian teachers defined health in terms of feelings of "well-being" $(40 \%)$. However, in contrast to Baumann's (1961) findings, Brazilian teachers defined health in terms of "Health Practices" (14.5\%) and the notion of health as an "Absence of Disease" was less frequently found (6.0\%). It was also noteworthy that though Brazilian teachers conceptualized health as a "Good Physical Condition" $(23 \%)$ an emphasis on role-performance capability (Baumann, 1961) did not appear in their answers.

When the use of a concept increases considerably, developing better ways to measure it are more than welcome. Interested in clarifying issues regarding dimensionality of the health concept, Laffrey (1986) concentrated efforts towards constructing a 28item scale to measure adults' health concept. Items were written in a Likert-scale format, and were tailored at representing each of the four models of health suggested by Smith (1981): clinical, role-performance, adaptative and eudaimonistic. The revised scale was administered to a sample of 141 predominantly female masters level students. Results showed that the Laffrey's (1986) Health Concept Scale had both reliability, as well as content and construct validity. Factor analysis lent support to the existence of the four aforementioned dimensions in the concept of health.

Other studies with adults have attempted to establish links between health concept and health attitudes, behaviors and behavioral orientations. Laffrey's $(1983,1986)$ previous findings provided some evidence that different views of health were associated with engagement in distinct types of health practices. Individuals who had a more eudaimonistic view of health engaged more in health enhancement behaviors, while individuals with a more clinical view of health were more oriented towards strict illness-avoidance and curative practices. In addition, in contrast to Baumann' (1961) findings, health concept was found to be 
unrelated to subjects' health status in Laffrey's studies. Therefore, Laffrey $(1983 ; 1986)$ called attention to the fact that to understand individuals' behavior or behavioral orientations, the health concept may be even more important than their health status.

Also attempting to explore potential links between concept of health and actual behavior, Segall \& Wynd (1990) examined the value of health concept, health locus-of-control and power as predictors of success or failure in smoking behavior change among 64 adults who had participated in a community smoking cessation program six months earlier. In respect to smoking status, $50 \%$ of the subjects reported successful abstinence, while the other $50 \%$ continued to smoke or resumed smoking after initial attempts to quit. Laffrey's (1986) Health Conception Scale, Wallston, Wallston \& DeVillis' (1978) Health Locus of Control Scale and Barrett's Power as Knowing Participation in Change Test (PKPCT) were administered to the sample through mailed questionnaires. Results demonstrated that successful abstainers had an eudaimonistic view of health and a more internal locus of control. Failure to stop smoking was associated with a clinical conception of health, an external locus of control, and a lower score for power.

\section{The Meaning of Health: Integrating Results of Children, Adolescents and Adults}

Taken together, studies with children, adolescents and adults revealed that health conceptualizations revolve mostly around the three major concepts of health described previously in this paper: the traditional medical concept, the ecological concept and the World Health Organisation concept. It was interesting to note however, that unlike the majority of adults, children and adolescents also included notions of preventivemaintenance practices in their definitions of health. In all age groups, it was usual to associate health with a functioning condition and with the ability to do the desired or required activities, but it was rare to define health in terms of a certain capacity to adapt to environmental changes, or in terms of normality.

Although not all of the studies with children and adolescents analyzed thematic diversity in subjects' answers, there was some evidence that the use of multiple ideas to define health increased with age (Natapoff, 1978; Millstein and Irwin, 1987). Findings from research with adults confirmed this trend. Health was defined with multiple ideas in most of the studies with adults (Baumann, 1961; Laffrey, 1983, 1986; Segall and Wynd, 1990). These results also lent support to the multidimensionality of the construct health.
In contrast to studies with children and adolescents, investigations with adults were more oriented towards exploring relationships between individuals' health concept and other health relevant variables such as: health behaviour, behaviour choices, health attitudes, as well as health status (Baumann, 1961; Laffrey, 1983, 1986; Segall and Wynd, 1990). Health concept was found to be related to engagement in health enhancement or disease preventing practices. Besides the influence of health relevant variables in the adults' health concept, differences were also found to be due to age, SES, religious affiliation and educational background (Baumann, 1961).

Studies reviewed in all age groups were carried out with satisfactory sample sizes and were mostly based on healthy samples. Research with both children and adolescents, as well as with adults was correlational in nature. However, research undertaken with children and adolescents were much more frequently based on relatively few static variable approaches, than were studies with adults. Unlike adult research, all the findings from younger age groups were heavily based on a few interview questions. Actually, it was not until 1986 that the Laffrey's Health Conception Scale, a significant methodological improvement over the interview, was developed. As this new instrument is not suitable for children and younger adolescents, a need for further research aimed at improving the assessment of health conception in younger age groups still exists.

\section{The Meaning of Illness}

Although the concept of illness appears to be an objective construct when compared to the concept of health, a closer look at some philosophical issues which underlie illness definition reveals that it might not necessarily be the case. As indicated by Balog (1978), finding an appropriate and encompassing definition of illness may be as difficult as a task as it is to define health. That is while no one would reject the notion that improper functioning and deviation from normality are essential components of illness, it might be not so easy to establish agreement concerning what constitutes proper functioning and what characterizes a deviation from normality.

There is reason to believe that an individual may be functioning improperly, though not regarded as ill. Lack of observable or felt symptoms are also not good delimiters of a non sick state. Moreover, medical professionals and lay persons differ in their judgements and interpretations of symptoms and signs. Thus, what is considered as a "sick condition" by the former group may not be so designated by latter. Value judgements and social norms have played a strong role, not only in 
defining health, but also in defining illness. Despite the aforementioned problems in obtaining a universally valid concept of illness, the importance of understanding individuals' ideas of illness and illness-related issues (for both enhancing health, and promoting adaptive coping) has been well demonstrated by empirical evidence.

\section{Empirical Studies with Children, Adolescents and Adults}

There has been a considerable amount of research on several illness-related concepts. However, the literature specifically on how people conceptualize illness is sparse. Some studies have attempted to describe how children, adolescents and adults define the meaning of illness. Studies with children and adolescents were predominantly targeted at identifying qualitative differences in illness concepts as a function of age and of other predictor variables (Apple, 1960; Campbell, 1975; Natapoff, 1978; Millstein, Adler \& Irwin, 1981; Redpath and Rogers; 1984; Millstein \& Irwin, 1987; Boruchovitch, Felix-Sousa, \& Schall, 1991; Boruchovitch, 1993; Boruchovitch \& Mednick, 1997).

In contrast, studies with adults were mostly based on the Illness Representation Approach. These latter investigations were more oriented not only towards exploring the underlying structural components individuals use to represent illness, but were also attempting to identify the relationships between individuals' illness representations and their engagement in health-related behaviours (Leventhal, Meyer \& Nerenz, 1980; Leventhal \& Nerenz, 1983; Meyer, Leventhal \& Gutmann, 1985; Skelton \& Croyle, 1991).

For the most part, data support the view that there are both developmental trends and similarities across-age groups in individuals' conceptualizations of illness. There is some consensus that "Somatic Feeling States" are the most frequent delimiters of illness (Campbell, 1975; Natapoff, 1978, Millstein, Adler \& Irwin, 1981; Millstein \& Irwin,1987; Boruchovitch, Felix-Sousa \& Schall, 1991). There seems also to be more agreement than disagreement that with age, children tend to define illness in terms of an "Alteration in Individuals' Functioning" (Apple, 1960; Campbell, 1975; Natapoff, 1978; Millstein, Adler \& Irwin, 1981). Moreover, it appears that with age, subjects conceive of health and of illness as distinct and multidimensional constructs (Millstein \& Irwin, 1987; Boruchovitch, 1993; Boruchovitch \& Mednick, 1997). No gender, no SES or ethnicity orientations emerged. Age was the strongest predictor variable impacting individuals' conceptualizations of illness.
The Meaning of Illness: Studies Based on the IllnessRepresentation Approach

Which are the major structural components individuals use to mentally represent illness? This question has received considerable attention from those who advocate the Illness Representation Framework (Leventhal, Meyer \& Nerenz, 1980; Leventhal \& Nerenz, 1983; Meyer, Leventhal \& Gutmann, 1985; Skelton \& Croyle, 1991). According to the current literature, there seems to be accumulating evidence for the existence of at least five components that make up lay people's appraisal of different illnesses. These components are: Identity, Time-Line, Consequence, Cause and Cure (Meyer, Leventhal \& Gutmann, 1985; Leventhal et al., 1990; Lau \& Hartman, 1983; Lau, Bernard \& Hartman, 1989; Skelton \& Croyle, 1991).

Goldman, Whitney Saltiel-Granger \& Rodin (1991) developed a study to ascertain whether children tend to employ the same five components in their concepts of illness dimensions of illness representation found in the research with adults. Findings revealed that, for the most part, preschool children whose age ranged from four to six years old demonstrated illness representation similar to that of adults. Although children lacked the ability to provide a complex causal explanation of how illnesses are acquired, they seemed to agree that illnesses have causes. The majority of the subjects also provided answers involved with strategies to cure illnesses. Moreover, children demonstrated an understanding of their role in the healing process. With respect to the dimensions duration and time-line, children seemed to grasp the notion that common illnesses usually do not last for longer periods of time. Concerning consequences of illness, the majority of them understood not only that illnesses have effects, but also that specific illnesses have specific outcomes.

It was interesting to observe that the Cure component was not salient in studies based on samples with chronic disease problems. Furthermore, the five aforementioned components of illness concept seem to be consistent over time and across different disease. Identity was the illness component most associated with predisposition to seek a health professional because this component implies a certain recognition of the presence of the disease which in turn function as a type of knowledge or clue that guides the individual to seek help (Lau, Bernard \& Hartman, 1989).

Although findings from the research on illness conceptualizations as a function of socio-demographic predictor variables, and those results from the studies based on the Illness Representation Framework may seem different in perspective, a closer examination reveals that differences may be more apparent than real. 
It seems that categories found in the former investigations could well fit into those five components proposed by the research from the Illness Representation Approach. One would easily agree that an "Alteration in the Individuals' Functioning”, category consistently found in studies which did not employ the Illness Representation Approach, is nothing more than the "Consequence" component suggested by the Illness Representation approach. Also in line with that, one may speculate that the component "Identity" (symptoms and labels of a given disease) is equivalent to the category "Symptoms and Somatic Feeling States", frequently found by the first group of studies (not based on the Illness Representation). Moreover, developmental trends and similarities across different age-groups were also found in the investigations based on the Illness Representation Framework. Continuing patients had a more accurate understanding of their disease than did their newly treatment and re-entry counterparts. Besides, research with young children also indicated that the five components of illness representation may well be present in children' cognitive repertoire (Goldman et al., 1991).

The Meaning of Health, the Meaning of Illness and Health Psychology: Some Remarks

The importance of understanding individuals' ideas of health and illness for health behaviour, health care, health prevention and promotion has been emphasised by a bulk of research (Rashkis, 1965; Millstein \& Irwin, 1987; Natapoff \& Essoka, 1989; Troccoli, Keller \& Nobrega, 1991; Contini, 2000). Health psychology is an important emerging field which can strongly contribute to help health professionals enlarge their own concepts of health, conceive man in its totality, and construct a culture of health promotion (Fonseca, 2001).

In addition to individuals' health concepts, psychological variables and emotions have an impact on their engagement in healthy related behaviours, as well (Lafreey, 1983, 1986; Segall \& Wynd, 1990; Seligman \& Cskiszentmihalyi, 2000). Accordingly, another relevant task of health psychology is to uncover the major psychological correlates of one's adherence to healthpromoting and health-impairing lifestyles.

At a historical time in which prevention of a great number of fatal diseases is within the human's control, desirable actions towards personal health are even more emphasized (Boruchovitch \& Mednick, 1999). Kaplan (2000) argues that while secondary prevention has limited benefits, primary prevention, through the promotion of healthy behaviours, shows promising results in improving the health of Psico-USF, v. 7, n. 2, p. 175-183, Jul./Dę. 2002 populations, and, therefore, should be the major goal of health policies. Ewart (1991) considers that health psychology should empower individuals not only towards the development of self- protective initiatives, but also towards the change of laws and policies to improve social environmental conditions that usually contribute as threats to public health.

In fact, health promotion efforts should not only take into account health and illness dimensions of children, adolescents and adults possess, but also should go beyond these dimensions in order to help individuals develop a more complete view of health, enhancing self-actualization, self-fulfilment and quality of life (Boruchovitch \& Mednick, 1997). No doubts exit that such a concept can only be achieved by improving the level of development of society as a whole (RamosCerqueira, 1994).

Besides contributing to rethink individuals' meaning of health and illness disseminated by the medical models (Moniz \& Reis, 2000), it is equally important that health psychology and other human sciences occupy their actual place in the health area, which has been predominantly dominated by biological and medical sciences. In consonance, health psychology has an important challenge to address: to promote a multidisciplinary view of man who experiences the process of health and illness in a way that health and illness can be conceived not only in terms of the individuals, but also in terms of their interrelations with society and its political systems, as well (RamosCerqueira, 1994).

\section{References}

Altman, D. G. (1982). Understanding health attitudes and conceptions of health and illness developmentally: implications for health education. Unpublished manuscript presented at American Psychological Association Annual Meeting, Washington, DC.

Apple, D. (1960). How laymen define illness. Journal of Health and Human Behavior, 1, 219-225.

Balog, J. E. (1978). An historical review and philosophical analysis of alternative concepts of health and their relationship to bealth education (Unpublished dissertation). Maryland: University of Maryland.

Balog, J. E. (1981). The concept of health and the role of health education. The Journal of School Health, 9, 462-464.

Bauer, W. W. \& Schaller, W. E. (1955). Your Health Today. New York: Harper and Row. 2nd Edition. 
Baumann, B. (1961). Diversities in conceptions of health and physical fitness. Journal of Health and Human Behavior, 2 (1), 39-46.

Boruchovitch, E. (1993). Health and illness-related cognitions among Brazilian students: a cross-cultural contribution. (Tese de doutorado). Los Angeles, Estados Unidos: University of Southern California Faculdade de Educação.

Boruchovitch, E. \& Mednick, B. R. (1997). Crosscultural differences in children's concepts of illness. Revista de Saúde Pública, 31 (5), 448-56.

Boruchovitch, E. \& Mednick, B. R. (1999). Causal attributions in Brazilian children reasoning about health and illness. Revista de Saúde Pública, 35 (5), 484-90.

Boruchovitch E., Felix-Sousa I. C. \& Schall V. T. (1991). Health Concept and Health Prevention in a sample of Teachers and Students: A contribution for health education, Revista de Saúde Pública, 25, 418-25.

Campbell, J. D. (1975). Illness is a point of view: the development of children's concept of illness. Child Development, 46, 92-100.

Contini, M. L. J. (2000). Discutindo o conceito de promoção de saúde no trabalho do psicólogo que atua na educação. Psicologia, Ciência e Profissão, 20 (2), 46-59.

Dolfman, M. L. (1973). The concept of health: an historic and analytic reexamination. The Journal of School Health, 43, (8), 491-497.

Dolfman, M. L. (1974). Toward operational definitions of health. The Journal of School Health, 44, (4), 206-209.

Dubos, R. (1965). Man Adapting. New Haven: Yale University Press.

Dunn, H. L. (1959). High-level wellness for man and society. Am. J. Pub. Health, 49, (6), 786-792.

Eberst, R. M. (1984). Defining health: a multidimensional model. Journal of School Health, 54 (3), 99-104.

Ewart, C. K. (1991). Social action theory for a public health psychology. American Psychologist, 46 (9), 931946.

Fonseca, M. S. (2001). Cultura da prevenção e formação de professores. Revista Educação e Ensino 6 (1), 25-30.

Goldman, S. L., Whitney-Saltiel, D., Granger, J. \& Rodin, J. (1991). Children's representation of everyday aspects of health and illness. Journal of Pediatric Psychology, 16 (6), 747-766.

Hinkle, L. E. (1961). Ecologic observations of the relation of physical illness, mental illness and social environment. Psychosomatic Med., 23 (4), 289-290.

Hoyman, H. (1962). Our modern concept of health. Journal of School Health, 32, 253.

Kalnins, I. \& Love R. (1982). Children's concepts of health and illness - and implications for health education: an overview. Health Education Quartely, 9 (23), Summer/Fall.

Kaplan, R. M. (2000). Two pathways to prevention. American Psychologist, 55 (4), 382-396.

Laffrey, C. S. (1983). Health behavior choice as related to self-actualization and health conception. Western Journal of Nursing Research, 7 (3), 279-300.

Laffrey, C. S. (1986). Development of a health conception scale. Research in Nursing \& Health, 9, 107-113.

Lau, R. R. \& Hartman, K. A. (1983). Common sense representations of common illnesses. Health Psychology, 2, 167-185.

Lau, R. R., Bernard, T. M. \& Hartman, K. A. (1989). Further explorations of common-sense representations of common illnesses. Health Psychology, 8 (2), 195-219.

Leventhal, H. \& Nerenz, D. (1983). Implications of the stress research for the treatment of stress disorders. In D. Meichenbaum \& M. Jaremko (Ed.). Stress reduction and prevention. New York: Plenum, p. 5-38.

Leventhal, H., Meyer, D. \& Nerenz, D. (1980). The common sense representation of illness danger. In S. Rachman (Ed.). Contributions to medical psychology. New York: Pergamon Press, v. 2, p. 17-30.

Lewis, A. (1953). Health as a social concept. British Journal Society, (4) 110-115.

Meyer, D., Leventhal, H. \& Gutmann, M. (1985). Common-sense models of illness: the example of hypertension. Health Psychology, 4 (2), 115-135.

Millstein, S. G., Adler, N. E. \& Irwin, C. E. Jr. (1981). Conceptions of illness in young adolescents. Pediatrics, 68 (6), 834- 839.

Millstein, S. G. \& Irwin, C. E. Jr. (1987). Concepts of health and illness: different constructs or variations on a theme? Health Psychology, 6 (6), 515-524.

Moniz, J. L. \& Reis, J. (1991). Desenvolvimento e dialética de significações de doença e confronto em psicologia da saúde. Psychologica, 6, 105-127.

Natapoff, J. N. (1978). Children's views of health: a developmental study. Americam Journal of Public Health, 68, 995-1000. 
Natapoff J. N. \& Essoka G. (1989). Handicapped and able-bodied children's ideas of health. Journal of School Health, 59 (10), 436-439.

Oberteuffer, D. (1960). School Health Education. 3rd Edition. New York: Harper and Brothers.

Parsons, T. (1958). Definitions of health and illness in the light of American values. In Jaco E. F. (Ed.). Patients, Physicians, and Illness. Glencoe: The Free Press.

Ramos-Cerqueira, A. T. de Abreu. (1994). Interdisciplinaridade e psicologia na área da saúde. Temas em Psicologia, 3 (1), 37-41.

Rashkis, S. R. (1965). Child's understanding of health. Archives of General Psychiatry, 12, p. 10-17.

Redpath, C. C. \& Rogers C. S. (1984). Healthy young children's concept of hospitals, medical personnel, operations, and illness. Journal of Pediatric Psychology, 1, 29-39.

Schall, V. T., Jurberg, P., Boruchovitch E., Felix-Sousa I. C., Rozemberg B. \& Vasconcellos C. (1987). Health education for children - developing a new strategy. Proceedings of the Second International Seminar on Misconceptions and Educational Strategies in Science and Mathematics, Cornell University, Ithaca, New York, USA, (2) 390-403.

Segall, M. E. \& Wynd, C. A. (1990). Health conception, locus of control, and power as predictors of smoking behavior change. American Journal of Health Promotion,
4, (5) 338-334.

Segre, M. \& Ferraz, F. C. (1997). O conceito de saúde. Revista de Saúde Pública, 31 (5) 538-42.

Seligman, M. E. P. \& Cskiszentmihalyi, M. (2000). Positive Psychology an introduction. American psychologist, 55 (1), 5-14.

Skelton, J. A. \& Croyle, R. T. (1991). Mental representation in shealth and illness. Springer-Verlag New York Inc.

Smith, J. A. (1981). The idea of health: a philosophical inquiry. Advances in Nursing Science, 3, (3) 43-50.

Troccoli, B. T., Keller, M. L., Andrade, W. S. G. \& Nóbrega, R. C. (1991). Representações de doenças e sintomas em pessoas leigas: Dados preliminares. Psicologia, Teoria e Pesquisa, 6 (3), 281-293.

Wallston, K. A., Wallston, B. S. \& Devillis (1978). Perceived control and health. Current Psychological Research \& Reviews, 6, (1) 5-25.

Williams, J. F. (1946). Personal bygiene applied. Philadelfia: W B Saunders.

World Health Organization. (1947). Chronical of WHO, $1,1-2$.

Recebido em 04/09/2002

Reformulado em 12/11/2002

Aceito em 10//12/2002

Sobre a autora:

Evely Boruchovitch é psicóloga pela Universidade do Estado do Rio de Janeiro, Ph.D em Educação pela University of Southern California, Los Angeles, professora do Departamento de Psicologia Educacional da Faculdade de Educação da Unicamp.

Birgitte R. Mednick é graduada em filosofia pela Universidade de Copenhagen, Ph.D em Psicologia pela Columbia University, Nova York, professora associada do Departamento de Psicologia Educacional da University of Southern California, Los Angeles. 
